\title{
DE ÉPOCA MALDITA A EPOPEYA LIBERAL: UNA REVISIÓN HISTORIOGRÁFICA A LA ANARQUÍA CHILENA (1823-1830) ${ }^{1}$
}

\author{
Armando Cartes Montory \\ Universidad de Concepción \\ acartes@udec.cl
}

Los años que siguieron a la abdicación del Director Supremo Bernardo O'Higgins suelen conocerse y periodificarse como la Anarquía (1823-1830). A ello contribuyó la bistoriografía tradicional, al dar cuenta de la confusa sucesión de gobiernos, constituciones, movimientos militares y graves desórdenes que caracterizó a aquella década fundacional. Fue también una época de logros, tales como la consolidación de la emancipación nacional y el origen de ciertas instituciones y libertades civiles que perduraron. Se trató, en fin, de un tiempo -y eso es lo principal - en que se confrontaron alternativas y se adoptaron opciones fundamentales que definieron, desde entonces y hasta el presente, la organización política de Chile.

El periodo ha sido estudiado por muchos autores, con los sesgos propios de su tiempo y sus tramas politicas e ideológicas. Pretendemos revisar estas perspectivas en sus contextos, como ejercicio de historia intelectual y de los usos de la historiografía como dispositivo político. Se trata de confrontar perspectivas y representaciones del país, en un momento eje de su conformación como Estado.

PALABRAS ClaVE: Anarquía, construcción de Estado, historiografía-liberalismo.

\section{From an ACCURSED EPOCH to a LibERAL EPIC: A HistoriograpHICAL REVISION OF THE CHILEAN ANARCHY (1823-1830)}

The years that followed the abdication of Supreme Director Bernardo O'Higgins are usually known as the Anarchy (1823-1830). Traditional historiography contributed to this denomination, by which it means the confusing succession of governments, constitutions, military

1. Este trabajo fue elaborado en el marco del proyecto Fondecyt n. ${ }^{\circ} 1150363$, De civiles militarizados a militares civilizados, la construcción de las sociedades civiles en América latina en la mirada de los militares napoleónicos.

[Recibido: 1/2/18; Aceptado: 5/6/18] 
movements, and the serious chaos that characterized that foundational decade. That epoch was also a time of achievements, such as the consolidation of the national independence and the origin of several civil institutions and liberties that came to last in time. At the core of this epoch are the confrontation of alternatives and the adoption of fundamental options that have defined, until today, the political organization of Chile.

Many authors have studied this period, taking into consideration the particular characteristics of the time and the political and ideological conundrums involved. In this essay, we aim at reviewing these perspectives in their own contexts, as a way of performing an intellectual history and a sample of the use of historiography as a political tool. Our goal is to confront different perspectives and representations of the Chilean country at a pivotal moment of its formation as a nation-state.

KEYWORDS: Anarchy, State building, historiography-liberalism.

\section{Introducción}

Los años que siguieron a la abdicación del Director Supremo Bernardo O'Higgins, estuvieron caracterizados por una confusa sucesión de gobiernos, constituciones, movimientos militares y graves desórdenes. Fue también la época germinal de varias instituciones y libertades civiles que perduraron.

La historiografía tradicional la calificó y periodificó como la Anarquía (1823-1830) ¿Corresponde a una realidad histórica o fue, más bien, una invención historiográfica? La respuesta exige acreditar la gravedad del escenario de desgobierno extremo de aquella década; o bien concluir, por el contrario, que la calificación resulta de una construcción, destinada a legitimar la violenta guerra civil de 1829 y el orden autoritario que le siguió.

Nuestra mirada se aleja de esas visiones polarizadas. Sin desconocer el desgobierno y la violencia de la época, nos parece que su rasgo central fue otro: la confrontación de proyectos alternativos. El país osciló, en efecto, entre la instalación de un Estado multipolar (¿confederal?), multicultural y liberalmente más avanzado, versus el Estado forzadamente homogéneo y centralizado que finalmente se instauró. Fue en esta época cuando se incubaron las opciones fundamentales que definieron, desde entonces y hasta el presente, la organización política de Chile. Nos referimos a la consolidación de su independencia plena, su conformación como Estado-Nación, así como la opción por el republicanismo y la centralización política; procesos que, naturalmente, debían completarse en las décadas siguientes. De ahí la importancia de revisitar este período inicial, con una mirada moderna.

El período ha sido estudiado por muchos autores, con los sesgos propios de cada tiempo y sus tramas políticas e ideológicas. Pretendemos revisar estas perspectivas en sus contextos, como ejercicio de historia intelectual y de los usos de la historiografía como dispositivo político. Se trata de confrontar perspectivas y representaciones del país, en un momento eje de su conformación como Estado. 


\section{La historiografía como política}

«...Lircay da comienzo al régimen portaliano que organizará la República y dejará aplastada la anarquía hasta mil novecientos setenta».

Enrique Bunster, Crónicas Portalianas, 1977

Uno de los desafíos de la historiografía es apartarse de la subjetividad y la contingencia, a lo menos en la medida necesaria para mantener su pretensión científica. Aunque es vedado al historiador alcanzar la verdad de los hechos, no puede renunciar, sin embargo, como sostiene Roger Chartier, a la práctica de ciertas operaciones o métodos propios de la disciplina ni a la aspiración de dar una cuenta honesta y justificada de los eventos. ${ }^{2}$ Atrapado, a su vez, el relato en la narración, las sutilezas del lenguaje y del estilo — tanto como los silencios - aportan una carga adicional de discrecionalidad. ${ }^{3}$

Las dificultades expuestas, comunes a todo ejercicio historiográfico, resultan más evidentes en la llamada historia del tiempo reciente. Implica hacer justicia a los actores cuando están todavía vivos y dominados por las pasiones de su tiempo; los documentos no están todavía reunidos o liberados, o los hechos no han decantado. ${ }^{4}$ Es complejo, pero es posible, según sostenía Marc Bloch. Él mismo, Michelet y muchos otros grandes historiadores del pasado o del presente así lo han demostrado.

Cada generación de historiadores ha debido asumir estos desafíos, al referirse a su propio tiempo. Cuando se abordan los eventos de un pasado más remoto, en cambio, aparentemente más pacífico, hay que enfrentarse a las visiones canónicas ya establecidas, así como a los prejuicios vigentes al tiempo de quien escribe. Lo anterior es notorio cuando pretendemos volver sobre los grandes procesos que han afectado a la sociedad de la que el historiador forma parte; más todavía cuando él mismo es un actor político, cosa frecuente en los autores clásicos chilenos. ${ }^{5}$ Las complejidades del oficio histórico alcanzan el cenit cuando la interpretación del pasado determina o se alinea con una determinada visión del presente. Allí la Historia se constituye en arma de legitimación política, alejándose de su pretendida — e improbable— asepsia política.

2. Cf. Chartier, Roger, El mundo como representación. Historia cultural: entre práctica y representación, Barcelona, Gedisa, 1996.

3. Cf. White, Hayden, Metabistoria. La imaginación bistórica en la Europa del siglo XIX, México D.F., Fondo de Cultura Económica, 2010, p. 11; e Iggers, Georg G., La bistoriografía del siglo XX. Desde la objetividad cientifica al desafío posmoderno, Santiago, Fondo de Cultura Económica, 2012, pp. 193 y ss.

4. Bédarida, François, «Definición, método y práctica de la Historia del Tiempo Presente», Cuadernos de Historia Contemporánea, n. ${ }^{2}$ 20, Madrid, 1998, p. 19.

5. Los ejemplos son muchos: Benjamin Vicuña Mackenna fue diputado e intendente de Santiago; Diego Barros Arana, hombre público y diplomático; y Domingo Santa María, autor de la memoria histórica Sucesos ocurridos en Chile desde la caída de O'Higgins hasta la promulgación de la constitución de 1823, fue Presidente de Chile (1881-1886). 
La historia de Chile está plagada de momentos y procesos que han sido sometidos a estos usos políticos. Los personajes tampoco se han librado de sufrir la manipulación maniquea de la historia comprometida. Diego Portales, el gran parteaguas de la historia de Chile, encarna en su figura la división política, por lo que recibe constantes apologías y vapuleos. ${ }^{6}$ Bernardo O'Higgins, «el Padre de la Patria», pero cuyos restos recién pudieron volver a Chile en 1869, ¡27 años después de su muerte!, ha sufrido una travesía igualmente accidentada por la historia. Loado por el poeta comunista Pablo Neruda en el Canto General y admirado por Salvador Allende, el uso simbólico de su figura por el Gobierno Militar, lo condenó —otra vez- al ostracismo de los dictadores, por los historiadores progresistas. Gabriel Salazar lo trata muy mal ${ }^{7}$ y un cronista superventas lo coloca con gafas oscuras —emulando al General Augusto Pinochet- en la portada de su Historia secreta de Chile. ${ }^{8}$

Aplicadas estas disquisiciones al estudio de la Independencia de Chile y al período inicial de la organización de la república, aparece probada la imposibilidad de una historiografía neutra o ajena a las perspectivas y demandas del momento. De manera honesta e inadvertida, en ocasiones, o de forma deliberada e intencionada, en otras, la historia toma posición y cumple funciones políticas o ideológicas. Ya sea desde la trinchera política o en la pedagogía cívica, en la pluma de los historiadores los eventos y sus interpretaciones se subordinan a valores como el orden, la libertad o el progreso. Una mirada teleológica de la cual nunca nos liberaremos totalmente.

Muy tempranamente, en plena Restauración Monárquica (1814-1817), la intención de conservar la memoria de los eventos que se vivían, de cuya historicidad muchos eran conscientes, se refleja en el encargo del Rey de confeccionar una crónica fidedigna. Fray Melchor Martínez, por su ilustración y algunos trabajos previos, fue el encargado de la tarea. Aunque quedó incompleta, por su precipitada fuga tras la Batalla de Chacabuco, las páginas redactadas y los documentos reunidos han sido de gran utilidad para la historiografía posterior; no solo por los eventos que describe, sino por los juicios y miradas que trasuntan del texto. ${ }^{9}$

En la etapa germinal de la nación chilena, la historiografía cumplió un rol deliberado en el proyecto de construcción cultural, que impulsó el Estado. Junto a símbolos, fiestas,

6. Pueden revisarse en: Cartes Montroy, Armando, «¿Estadista «en forma» o falsificación histórica? Diego Portales ante la historiografía chilena», Bancalari Molina, Alejandro, Rojas Gómez, Mauricio, Valdés Urrutia, Mario y Ventura Rojas, José Manuel (eds.), Concepción y el Bicentenario, Departamento de Historia y Ciencias Sociales Universidad de Concepción, 2012, pp. 155-166.

7. Dice de él, en efecto, que «si bien su pensamiento era en última instancia republicano, su desempeño dictatorial desmerecía en los hechos ese pensamiento, y si provenía de la tradición democrática de los pueblos, la forma autocrática y conspirativa de muchas de sus decisiones como gobernante diluyeron esa tradición hasta anonadarla (sic)...», Salazar, Gabriel, Construcción del Estado en Chile (1800-1837), Santiago, Editorial Sudamericana, 2005, pp. 154-155.

8. Baradit, Jorge, Historia secreta de Chile 2, Santiago, Editorial PRH (Sudamericana), 2016.

9. Martínez, Fray Melchor, Memoria histórica sobre la Revolución de Chile desde el cautiverio de Fernando VII hasta 1814, Valparaíso, Imprenta Europea, 1848; reedición en dos volúmenes, por el Fondo Bibliográfico José Toribio Medina, Santiago, 1962 y 1964. 
las mismas guerras o los funerales de hombres de Estado, formó parte de las liturgias republicanas, destinadas a consolidar un imaginario nacional. ${ }^{10}$

Los primeros estudios sobre la historia patria, que cubrían el período de la Independencia y la década siguiente, fueron patrocinados por el gobierno conservador que integraba el Ministro Diego Portales. El naturalista francés Claudio Gay fue contratado para escribir también la historia «política» de Chile. ${ }^{11}$ Junto a las memorias históricas que se leyeron en la Universidad de Chile, publicadas a partir de 1844, la Historia Física y Politica de Chile es de las bases fundacionales de la historiografía nacional. En ella, Gay promovía una visión teleológica y binaria del pasado. En su perspectiva, la culminación de la historia coincide con el orden y la estabilidad alcanzados bajo el gobierno del Presidente Joaquín Prieto y su ministro Diego Portales. Los años transcurridos desde la renuncia de O’Higgins hasta la asunción de Prieto resultan un estado inferior y necesario en el camino de la organización política, iniciado en la gesta revolucionaria y concluido con la promulgación de la Carta Constitucional de 1833. La victoria sobre la banda de los Pincheira era el triunfo del régimen portaliano contra la barbarie. Del orden sobre la anarquía. Terminaba con ello la independencia, «tercer período de la historia chilena» y — siempre según Gay - se inauguraba el cuarto: el de «la libertad y la civilización». ${ }^{22}$ Este pensamiento, aunque con matices, fijaría el canon durante todo el siglo XIX.

En adelante, la historiografía conservadora y defensora del estado portaliano endurecería la visión sobre la condición anárquica y de desorden general que se vivió en el período de 1823 a 1830, con el trasfondo del gobierno autoritario que se implementó en la Carta de 1833. En ese contexto, la «anarquía» sirvió a los propósitos de progreso y legitimación histórica a que aspiraba el peluconismo. Temprano se abrieron, no obstante, grietas liberales a la mirada crítica de la época.

\section{Conceptos, problemas y perspectivas}

La anarquía fue un momento común en varias incipientes naciones americanas, que salían de las guerras de independencia con sus sociedades divididas, su economía paraliza$\mathrm{da}$, dislocado el control social y sin haber construido una identidad nacional que diera legitimidad al gobierno y cohesión a la población. ${ }^{13}$ Había que dar un cauce institucional

10. Véase por ejemplo, Pedemonte, Rafael, Los acordes de la patria. Música y nación en el siglo XIX chileno, Santiago, Globo Editores, 2008; Peralta, Paulina, ;Chile tiene fiesta!, el origen del 18 de septiembre (1810-1837), Santiago, Editorial LOM, 2007; Valencia Avaria, Luis, Símbolos Patrios, Santiago, Gabriela Mistral, 1974; y Mc Evoy, Carmen (ed.), Los Funerales Republicanos en América del Sur: Tradición, Ritual y Nación 1832-1896, Santiago, Centro de Estudios Bicentenario e Instituto de Historia Pontificia Universidad Católica de Chile, 2006.

11. La Historia Física y Política de Chile se concluyó en París, en el lapso de 27 años, entre 1844 y 1871. La forman 30 volúmenes, que incluyen los 8 de la Historia, más dos con los documentos justificativos de ella.

12. Gay, Claudio, Historia Física y Política de Chile, tomo VIII, París, editado en casa del autor, 1871, p. 346.

13. «Por lo mismo que es una etapa de crisis, dice Ricardo Levene, para el caso argentino, debe ser estu- 
a la nueva lógica del pueblo soberano, influido por el liberalismo, pero atrapado todavía en pervivencias coloniales en diversos ámbitos.

En la política chilena — de la cual la Historia es también campo de batalla- la «dictadura» y la «anarquía» son los adjetivos con que se descalifican los extremos del espectro. Así ha ocurrido en diversos momentos de su historia republicana; de ahí la importancia del lenguaje en la creación de realidades y percepciones.

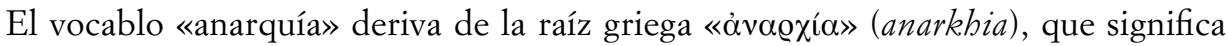
«sin jefe o gobierno». Conforme a Malatesta, corresponde a «la vida de un pueblo que se rige $\sin$ autoridad constituida, sin gobierno». ${ }^{14}$ Podría también asociarse a una «flaqueza de la autoridad», ${ }^{15}$ no necesariamente a la falta total de la estructura gubernamental. También se aplica al «estado de hecho de un grupo social que no se sujeta a autoridad alguna» y, en esta acepción, corresponde a una filosofía de vida en comunidad utópica. Como ideología y movimiento político y social, surge en la segunda mitad del siglo XIX y se desarrolla en el siglo XX. ${ }^{16}$ No era el caso en 1820, en que no existió facción o bando político alguno de ideales anarquistas, sino más bien una pugna de poder entre elementos oligárquicos. ${ }^{17}$

En su acepción de desgobierno el término anarquía contiene una fuerte carga peyorativa. Así era en la época en estudio, según se aprecia en el tono desdeñoso con que lo utilizaba la prensa; también ciertos actores políticos, asociando el término a la democracia o el federalismo, según sus preferencias políticas. Es conocido, al efecto, el escrito del francés Dauxion Lavaysse, Del Federalismo y la Anarquía, impreso en Santiago en 1823:

Consideremos, pues, que según las circunstancias intelectuales y morales actuales de la masa del pueblo chileno, el sistema federal, en su sentido absoluto, no serviría sino para hacer retroceder nuestra civilización, porque no produciría sino la anarquía. ${ }^{18}$

Por su carga negativa, autores modernos prefieren el concepto de crisis (Heise) o de ajustes estructurales, para referirse a las convulsiones y cambios profundos de las instituciones que se vivieron en la segunda década de la revolución chilena.

En cuanto a las periodificaciones aplicadas a la anarquía, el consenso está lejano. Ello resulta de que las aproximaciones a la época están condicionadas por el ánimo de relevar

diada a conciencia, sin omitir hechos que tienen la apariencia del ápice y son síntomas de tiempos nuevos». $C f$. Levene, Ricardo, La anarquía del año 20, Buenos Aires, Unión de editores latinos S.R.L., 1954, p. 29.

14. Malatesta, Ericco, La Anarquía, Puebla, Premiá editora de libros S.A., 1989, p. 7.

15. González Marrero, Secundino, «Anarquismo», en Reyes, Román (dir.), Diccionario Crítico de Ciencias Sociales. Terminología Científico-Social, Tomos 1-4, Madrid-México, Ed. Plaza y Valdés, 2009.

16. Cf. Nicolas, Walter, Sobre el Anarquismo, Santiago, Editorial Eleuterio, 2016, pp. 19-20; y del Solar, Felipe y Pérez, Andrés, Anarquistas, presencia libertaria en Chile, Santiago, Ril Editores, 2008.

17. Para las discusiones conceptuales, cf. Márquez Ochoa, Boris, Anarquía en Chile: 1823-1830, ¿invención historiográfica o realidad histórica?, Tesis para optar al grado de Magister en Historia, Concepción, Universidad de Concepción, 2015.

18. Reproducido en Stuven, Ana María y Cid, Gabriel, Debates republicanos en Chile. Siglo XIX, vol. I, Santiago, Ediciones Universidad Diego Portales, 2012, pp. 412-440. 
determinados procesos. Las periodificaciones, ya lo sabemos, participan de la subjetividad de la Historia. La Independencia y la organización del Estado ofrecen un buen ejemplo al respecto. Si bien su inicio se suele situar en 1810, con la formación de la Primera Junta de Gobierno, la culminación del proceso es menos obvia. Algunos lo sitúan en la Declaración de Independencia y sus posteriores Proclamaciones (1 de enero de 1818, en Concepción y 12 de febrero del mismo año, en Santiago, Talca y otras ciudades, respectivamente); la Batalla de Maipú (5 de abril de 1818), lo que si bien sería válido para la zona central, más que para el sur, se justifica por la proyección americana de ese evento. Para Vicuña Mackenna, la llamada Guerra a Muerte corresponde a las «últimas campañas de la Independencia de Chile», cuyo fin fija en 1824. Pero bien podría defenderse que la independencia solo se consolida con la anexión de Chiloé (1826) o aún con la derrota definitiva de los Pincheira, hacia 1830, aunque estos fueron estertores de una guerra ya ganada.

Otros extienden la Emancipación al Gobierno de Bernardo O'Higgins; que sería seguido por el período de organización del Estado. Para nosotros, se trata, más bien, de procesos simultáneos, que se inician todos en 1810. La búsqueda de un nuevo orden político y la lucha por la redistribución territorial del poder, en efecto, comenzó con la creación de la Junta de Gobierno «provisoria», el 18 de septiembre de aquel año.

Es la mirada también de Gabriel Salazar a la «construcción del Estado». En su obra homónima, la enmarca entre los años 1800 y 1837, época que califica del «tiempo-madre de la historia política de Chile» y que culminaría con la muerte de Diego Portales. ${ }^{19}$ Tradicionalmente, sin embargo, se sitúa la llamada «anarquía» entre 1823 y 1830. Es el tiempo que media entre la abdicación de O'Higgins y la batalla de Lircay. Así, para Fernando Campos, siguiendo a Julio Heise, «el 28 de enero de 1823 iniciose en Chile la era del aprendizaje político». ${ }^{20}$ «La lucha por la organización del Estado (1823-1830)» rotulaba Luis Galdames, por ejemplo, en el capítulo respectivo de su Estudio de la Historia de Chile, ya en 1911. ${ }^{21}$ Son los mismos siete años en que Francisco A. Encina fija «Los ensayos de organización política democrática y la anarquía 1823-1830». Collier y Sater, en su Historia de Chile, en cambio, fijan la «busca del orden político», entre 1817 y 1830.22 Como se aprecia, las miradas más matizadas al período entrelazan la independencia con los años de des-organización que le siguieron.

En las aproximaciones a esta época pueden identificarse múltiples perspectivas. Pasaremos revista a cuatro momentos historiográficos. En cada uno de ellos puede identificarse el diálogo ineludible entre las obras y el momento de su producción. En primer lugar daremos una mirada a la historiografía del siglo XIX. Luego, para principios del

19. Salazar, Gabriel, Construcción del Estado..., cit., p. 22.

20. Campos Harriet, Fernando, Historia Constitucional de Chile, Santiago, Editorial Jurídica de Chile, 1992, p. 134. Campos rotula el capítulo respectivo «la lucha por la organización del estado 1823-1830».

21. Galdames, Luis, Estudio de la Historia de Chile, Santiago, Editorial Universitaria, 1911, p. 359.

22. Collier, Simon y Sater, William, A History of Chile, 1808-1994, Cambridge, Cambridge University Press, 1996, p. 52. 
siglo XX, es ineludible la visión de Alberto Edwards, por su influencia en Francisco A. Encina y varios autores posteriores. En la segunda mitad de aquel siglo, es importante la mirada de Julio Heise, quien valora positivamente el período, en el camino de la construcción de las instituciones y prácticas republicanas. En el mismo siglo y también de manera contemporánea, la historia social ha mirado críticamente las visiones tradicionales, para rescatar los años de 1823 a 1830 como una época de luchas sociales y transformaciones, abortadas por la reacción conservadora triunfante en Lircay, en 1830. Las obras de Luis Vitale y Gabriel Salazar grafican esta perspectiva.

En tiempos recientes, se ha reconocido el desorden extremo de aquel tiempo, pero evitando el apelativo peyorativo de anarquía. Parece imponerse una mirada más equilibrada de la situación chilena en el contexto americano. Se omite, no obstante, en nuestro concepto, una comprensión de los proyectos alternativos en juego, más allá de los intereses de grupos y las ambiciones personales. Y una valoración del cariz fundacional de esa década, en la adopción de definiciones que han caracterizado el orden republicano chileno.

\section{El juicio de la historia tradicional}

En la historia «clásica» chilena, que tradicionalmente se refiere a los autores del siglo XIX, varios de los cuales fueron actores de la organización republicana, la mirada al período es generalmente crítica. Es el caso, desde luego, de Diego Barros Arana y su obra mayor, la Historia General de Chile. En ella, la historia patria culmina - y reveladoramente también la Historia General- cuando el régimen pelucón logra imponer el nuevo orden, expresado en la Constitución de 1833. Similar conclusión alcanzan Claudio Gay, Miguel Luis Amunátegui y varios otros. En alguna medida, la obra tan sólidamente documentada de Barros, como meticulosa en la descripción de los eventos, impidió a los demás historiadores sustraerse totalmente a ella.

Una mirada crítica, desde la historia social, al relato de Barros Arana se debe a Gabriel Salazar. Este insinúa que la interpretación predominante del período 1810-1837 sería una oportunista construcción ideológica tendiente a justificar, tras la máscara encubridora de «la patria», la imposición abusiva de los intereses de un grupo particular a toda la nación. La maciza descripción de eventos, así como su rango de «héroe historiográfico», habrían inhibido la crítica. Atacando su supuesta objetividad, no duda en atribuirle a la obra «tesis políticas subliminales» que desnudan la afiliación «oligárquica, mercantil y pelucona» del autor.

Lo anterior sería especialmente notorio en su interpretación del período 1823-1837. Así resulta de la crítica acerba a la figura y actuación del general Ramón Freire, contradiciendo los propios hechos que relata. Lo mismo vale sobre el patriciado mercantil, que serían los verdaderos frondistas y anarquistas, según sus datos, mientras que declara que Freire y los liberales fueron los responsables de la «anarquía». Por estos y otros asertos, Barros Arana merece el mote de «intelectual antidemocrático», pues, a juicio de 
Salazar ha sido uno de los principales artífices de la (perversa) memoria política oficial de Chile».

Varios autores del período, en nuestra opinión, por otra parte, adolecen de un reduccionismo al campo político, dimensión que no alcanza por si sola a dar respuestas satisfactorias sobre esa década convulsionada. En este caso se hallan las obras tradicionales de historiadores del siglo XIX, como Ramón Sotomayor V. o el mismo Diego Barros Arana. Hubo varios que no pudieron apartarse demasiado de la sombra de Barros Arana o del mismo Andrés Bello. Las obras de historiadores e intelectuales liberales del período, como Benjamín Vicuña Mackenna, Miguel Luis Amunátegui, José Victorino Lastarria o Isidoro Errázuriz, aunque rescatan las luchas y logros de la «anarquía», suelen enmarcarse en las periodificaciones y abordan los procesos y personajes de la historia canónica.

Entre los defensores por esta época, se destacan José Victorino Lastarria (1817-1888) y Domingo Amunategui (1860-1946). El primero, agudo crítico liberal de la tradición conservadora, lo reivindicaba tempranamente: «Se ha hecho creer generalmente que la administración de los pipiolos era el tipo del desorden, de la dilapidación, de la injusticia y de la arbitrariedad. Pero semejantes acusaciones, hijas de la mala fe o de la ignorancia, caen al suelo cuando se hojean los boletines de las leyes de la época y se estudia un poco la historia». ${ }^{23}$ Domingo Amunategui se suma con estas palabras: «La época de nuestra Historia Nacional más censurada, más vilipendiada, más ridiculizada, ha sido la que empieza con la abdicación de O'Higgins y termina con el triunfo conservador en Lircay. Nada es más injusto». ${ }^{24}$

En una obra dedicada a reivindicar la figura de Freire, Julio Alemparte se suma a la defensa del período, aunque sin aportar mayores datos: «Bien se sabe que ese período es designado, generalmente, con el nombre de «Anarquía»; término bastante injusto, porque supone un caos inútil, cuando lo cierto es que fue fecundo en valiosas tareas y reformas y estuvo animado de nobles y generosos propósitos, que aprovecharon, precisamente, sus enemigos para producir disturbios y complicaciones y aumentar, así, esa inestabilidad política de que le culpan».25

En el campo conservador, una mirada representativa es la de Ramón Sotomayor Valdés (1830-1903). En su libro Historia de Chile durante los cuarenta años transcurridos desde 1831 basta 1871, aparecido en 1875, ampliado en 1900 y reimpreso en 1962, realiza una justificación de la revolución de 1829 y la instauración del orden autoritario. ${ }^{26} \mathrm{El}$ autor fue diplomático y periodista. Participó en el debate político a través de su trabajo

23. Lastarria, José Victorino, Obras Completas, tomo IX, Santiago, Imprenta Barcelona, 1906, p. 177.

24. Amunátegui Solar, Domingo, Pipiolos y Pelucones, Santiago, Universidad de Chile, 1939, p. 5.

25. Alemparte, Julio, Carrera y Freire, forjadores de la República, Santiago, Editorial Nascimento, 1963, p. 360 .

26. La obra originalmente sólo comprendía el primer gobierno de Prieto. Fue ampliada posteriormente para cubrir ambos y reimpresa, como segunda edición corregida, entre los años 1900 y 1903 . Fue reeditada por la Academia Chilena de la Historia, a través del Fondo Histórico Presidente Joaquín Prieto, en 1962, en 4 tomos, con el título de Historia de Chile bajo el gobierno del General Joaquín Prieto. 
histórico señalado y una biografía hagiográfica sobre Portales. ${ }^{27}$ Aunque recibió una educación liberal, en el Instituto Nacional y tuvo profesores como José Victorino Lastarria, Ramón Briceño y aún el economista francés Courcelle-Seneuil, derivó luego hacia ideas peluconas o conservadoras. Sus experiencias como diplomático acreditado en el México del Emperador Maximiliano y en Bolivia, atrapada entonces en la violencia política, tanto o más que su ideario conservador, le llevan a valorar el orden impuesto por Portales, aun a costa del despotismo. Asumió la defensa de la herencia hispánica y se transformó en un devoto católico.

La pretendida libertad, decía Sotomayor, si no se controlaba con un gobierno fuerte y autoritario, se transformaba en anarquía. ${ }^{28}$ Es la tarea que acometió Portales, de quién señala: «Necesitábase, en efecto, un brazo tan poderoso como aquél para arrostrar la anarquía y contener igualmente la reacción». ${ }^{29} \mathrm{La}$ obra de Sotomayor marca el rumbo que adoptará la historiografía conservadora: sólo hay libertad dentro del orden y éste justifica incluso eventuales excesos. ${ }^{30}$ De esta forma, su perspectiva contribuyó a valorizar y dar legitimidad política, desde la historia, a la actuación pública de Portales y el régimen conservador.

\section{Dos voces del siglo $\mathrm{XX}$}

Una perspectiva que hizo mucha escuela en el siglo Xx es la denuncia de la tendencia disolvente de la oligarquía, vista como un sujeto social contrario a un poder estatal fuerte. Es la visión de Alberto Edwards (1874-1932), ampliada y difundida por Francisco A. Encina, que se ha vuelto canónica. Se tradujo en una valorización de la figura de Diego Portales ya no como un líder del grupo estanquero y pelucón, sino como una figura que enfrenta y trasciende los propósitos de la aristocracia como clase. Casi con clarividencia, el Ministro Portales pudo ver más allá de los intereses de grupos, para sentar las bases de un orden republicano trascendente. Una proposición que requería, ciertamente, de una mirada muy crítica de la «anarquía», partiendo por el lenguaje.

Intentaremos una revisión de la visión conservadora, entre los intelectuales del siglo Xx, a través de Edwards, el primero y más influyente, quien en su libro La Fronda aristocrática, definió a la época estudiada como un «interregno anárquico». ${ }^{31}$ La situación

27. Sotomayor Valdés, Ramón, El Ministro Portales, Santiago, Ministerio de Educación Pública, 1954.

28. Sotomayor, Valdés, Ramón, Historia de Chile bajo el gobierno del General Joaquín Prieto, tomo I, Santiago, Academia Chilena de la Historia, 1962, p. 8 y ss.

29. Sotomayor Valdés, Ramón, El ministro Portales..., cit., p. 10.

30. Cartes Montroy, Armando, «Estadista 'en forma...», cit., p. 160.

31. Edwards Vives, Alberto, La Fronda aristocrática, Santiago, Editorial del Pacífico S.A., 1952. El libro se edita, por primera vez, en 1928 (Imprenta Nacional, Santiago), y reúne un conjunto de artículos de prensa. Se complementa con otras dos obras del autor: Bosquejo histórico de los partidos políticos chilenos, Santiago, Guillermo Miranda Editor, Imprenta Mejías, 1903 y La organización política de Chile, Santiago, Editorial del Pacífico, 1943. 
del país la describe en términos sombríos: «se vivió, pues, en la anarquía, y aunque no se derramó mucha sangre, ya que los motines, y golpes de Estado fueron por lo general incruentos, la desorganización social y política se presentaba de día en día más alarmante». ${ }^{32}$ A su juicio estábamos a punto de asimilarnos a otros países de América, donde el cesarismo se había entronizado, primero de forma «intermitente, inestable y anárquica», luego bajo la forma de «grandes despotismos duraderos». Aunque para Edwards, siguiendo la extendida visión de la «excepcionalidad chilena», el país se sustrajo a estos fenómenos, «tuvimos un remedo de aquel orden de cosas netamente sudamericano, durante los siete años que transcurren entre la caída de O'Higgins y la revolución de 1829».

Edwards es crítico del liberalismo que había calado en una importante porción de las élites, al que calificaba de «romántico y primitivo». No cabía hablar de república todavía, en su concepto, o de «infructuoso ensayo del régimen democrático», salvo por la ausencia de una dinastía. El constitucionalismo, elemento esencial del republicanismo, no se satisfacía con ideólogos que vivían encerrados en «el mundo de las leyes, de los discursos y de las abstracciones», descuidando las realidades. Superando incluso a su admirado Portales, en efecto, en el desprecio de constituciones y leyes escritas, consignó que, en aquella época, los jurisconsultos y los ideólogos «perdieron su tiempo redactando constituciones y discutiendo principios de derecho público». No se refiere a «esos trabajos completamente inútiles», pues lo estimaba «una puerilidad», limitándose a calificar de «sueños» el federalismo de José Miguel Infante y de «leyenda española en prosa» a la Carta que redactara José Joaquín de Mora en 1828. Solo Chile, entre las repúblicas españolas de América, concluye, lograría formar «una tradición constitucional, un régimen permanente y ordenado sobre bases jurídicas o morales, un «Estado en forma», según la feliz expresión de Spengler». Pero para ello debía esperarse a que Portales tomara las riendas del gobierno.

A la clase dirigente dedica sus mejores dardos. No fueron ni los «pipiolos genuinos», de efímero poder, ni los caudillos ambiciosos la causa de la mentada anarquía; ambos grupos más bien constituyeron la expresión o consecuencia de algo más profundo. Era la lucha entre fracciones de la oligarquía, que aspiraba, incluso de manera inconsciente y hereditaria, a la consideración y el mando, o al menos, a «un régimen organizado de influencias compartidas entre los miembros prominentes de la familia social de que todos formaban parte». Su liberalismo, a la manera aristocrática, se traducía en odio al poder personal. Así se manifestó en 1810, mediante el recurso a juntas, asambleas, congresos y ejecutivos débiles; y, andando el siglo, en las revoluciones violentas de 1859 y 1891. En síntesis, la historia política chilena del siglo XIX se explicaba como la oposición constante de la aristocracia a la constitución de un poder estatal autoritario, impersonal y centralizado; pero frente al cual, en coyunturas críticas, como en 1810 o para conjurar la anarquía, debe ceder, para asegurar las instituciones, el orden público y, al principio, a la iglesia.

32. Edwards Vives, Alberto, La Fronda aristocrática..., cit., p. 46. 
La revolución de 1830 debía ser una repetición más, aunque trágica y sangrienta, del juego perverso de las élites. La intervención de Portales, según Edwards, cambió un desenlace ya repetido y previsible. «El genial caudillo de la fronda» alzó sobre el caos confuso de los acontecimientos «un poder impersonal, evocación majestuosa del antiguo orden monárquico, un Gobierno erigido otra vez en fuerza moral permanente y obedecida, superior a las facciones políticas y a los prestigios militares». ${ }^{33}$ De esta forma, conjuró el peligro de una anarquía larga y sangrienta y dio paso al «Estado en forma», paradigma del gobierno ordenado y progresista que han preconizado los conservadores chilenos de distintas épocas.

La tesis central de Edwards se refiere a la reconstitución del poder impersonal, de orígenes coloniales, ahora bajo ropajes republicanos, bajo el influjo del ministro mártir. Con su visión y carácter, éste pudo doblegar temporalmente, lo suficiente para instalar las bases permanentes de un Estado constitucional, a la «fronda aristocrática» y sus tendencias a gobernar como clase, sin ceder a un poder centralizado. Su labor ordenadora solo existe y se justifica, en especial la sangrienta revolución que abrió el ciclo conservador, por la existencia de una anarquía comparable a la de nuestros países vecinos.

Su interpretación intenta dar una mirada panorámica a los eventos de 1820-1840, a casi un siglo de distancia. En su origen, no obstante, no puede sustraerse a las circunstancias de su tiempo, mostrando — una vez más — la historicidad de la historiografía. Es posible que la indolencia de las clases dominantes frente a la crisis social y la politiquería inconducente del parlamentarismo «a la chilena» hayan despertado en él un rechazo a la oligarquía y una adhesión al orden y el gobierno fuerte. Recordemos que apoyó con ardor al general Ibánez, de quien también luego se decepcionaría.

Su lenguaje mordaz, pero atrayente incluso para la misma oligarquía que denostaba, se dejó oír en el momento oportuno, cuando ya el liberalismo y su noción de un progreso constante se hallaban en decadencia. Su condición de ensayista intuitivo, liberado del pesado fardo del positivismo de los historiadores clásicos; su recurso — más o menoscientífico a la antropología, la sociología y otras ciencias emergentes, provocaron impacto. ${ }^{34}$ Por todo esto, su obra alcanza gran influencia.

Para Ricardo Donoso, Edwards es el «panegirista incondicional del régimen pelucón, admirador entusiasta de la Constitución de $1833 \ldots . .{ }^{35}$ La idea de un brevísimo «período caótico», de 1823 a 1830, tras el cual el Estado nacional se consolida por largo tiempo, es compartida por Mario Góngora, en su ensayo no menos influyente sobre la noción de Estado en Chile. Para él, se trata de «la mayor y la mejor interpretación de la historia del siglo pasado», que estructura el acontecer nacional desde 1830 hasta 1891, e incluso,

33. Edwards Vives, Alberto, La Fronda aristocrática..., cit., p. 49.

34. Sobre Edwards y su obra, cf. Gazmuri, Cristián, «Edwards y la Fronda Aristocrática», Historia, vol. 37, n. ${ }^{\circ}$ 1, Santiago, 2004, pp. 61-95; Perspectiva de Alberto Edwards, que reúne trabajos de Ignacia Alamos, Mariana Aylwin, Sofía Correa, Cristian Gazmuri y Juan Carlos González (Santiago, Editorial Aconcagua, 1976); y Silva Castro, Raúl, «Don Alberto Edwards», Revista Chilena de Historia y Geografía, n. ${ }^{\circ}$ 78, Santiago, 1933.

35. Donoso, Ricardo, Las ideas políticas en Chile, México D.F., Fondo de Cultura Económica, 1. a edición, 1946, p. 11. 
como un crepúsculo, todavía desde 1891 hasta $1920 .{ }^{36}$ Su influencia intelectual excedió al círculo de los historiadores conservadores. Así, Eduardo Frei Montalva escribió una continuación del Bosquejo bistórico de los partidos políticos chilenos, en el cual muestra suscribir al mito portaliano y, en general y con entusiasmo, las tesis de Edwards. ${ }^{37}$ Se publicó en un texto en que figuran ambos como autores. ${ }^{38}$

En razón de su débil base histórica, sin embargo, podría no haber perdurado. Pero ocurrió que, curiosamente, a través de la pluma del historiador Francisco A. Encina, igualmente rotunda y con mayor «autoridad» sobre la historia, las intuiciones de Edwards se proyectaron sobre la historiografía del siglo Xx, hasta devenir en el canon historiográfico, superando otros relatos mejor investigados, pero menos «perceptivos», que la propuesta del autor de La Fronda. Encina compartió la visión y la profundizó en su Historia de Chile desde la prehistoria hasta 1891, editada desde 1949 por la editorial Nascimento. En ella, el historiador maulino parece más influido por Edwards de lo que estaba dispuesto a reconocer. Incluso insinúa haberle sugerido muy tempranamente sus ideas, pero que luego decide publicarlas por sí mismo, convenientemente luego de la muerte del autor de La Fronda. ${ }^{39}$ Como sea, la visión de ambos intelectuales ha permeado a la sociedad, a través del sistema educacional, dando lugar a la interpretación más difundida de la historia de Chile. ${ }^{40}$

En las últimas décadas, el uso político de la figura de Portales y la exaltación del orden en que se empeñó el régimen militar han politizado su figura y desatado un fuerte revisionismo histórico. ${ }^{41}$ Este alcanzó al período previo que nos ocupa y a Ramón Freire y Francisco A. Pinto, sus principales figuras. ${ }^{42}$

En años recientes, se han multiplicado las miradas críticas, aun reconociendo el lugar que ocupa el ensayo histórico de Edwards, en el campo de las ideas. Para Cristián Gazmuri, la obra «es genial, aunque sus vacíos sean también muy notorios». ${ }^{43}$ Sergio Villalobos, por su parte, critica la denigración de la década «anárquica», por «ensayistas y estudiosos del pasado, apegados a la aristocracia y al autoritarismo». Ve en ellos un afán político, porque no coincide con sus ideas. «Pienso, principalmente, concluye, en Alber-

36. Góngora, Mario, Ensayo histórico sobre la noción de Estado en Chile en los siglos XIX y XX, Santiago, Editorial Universitaria, 2003, p. 74.

37. Gazmuri, Cristián, La historiografía chilena (1842-1920), tomo I, Santiago, Taurus, 2006, p. 199.

38. Edwards Vives, Alberto y Eduardo Frei Montalva, Historia de los partidos políticos chilenos, Santiago, Editorial del Pacífico, 1949.

39. Cf. Encina, Francisco Antonio, Portales, tomo I, Santiago, Editorial Nascimiento, 1964, p. 13.

40. Es tal su influencia, que alcanza a quienes claramente no tienen una visión conservadora de la sociedad. Es el caso por ejemplo, de Aníbal Pinto Santa Cruz, autor del conocido libro Chile. Un caso de desarrollo frustrado, aparecido en 1959. De las 139 citas del libro, 29 son de Encina, Francisco Antonio (Gazmuri, Cristián, La bistoriografía chilena..., cit., p. 199).

41. Véase por ejemplo, Salazar, Gabriel, Construcción del Estado ..., cit.; y Cartes, Armando, «¿Estadista 'en forma...», cit.

42. Cf. Salazar, Gabriel, Construcción del Estado..., cit.; Luis Ossa, Juan, «La actividad política de Francisco Antonio Pinto: 1823-1828. Notas para una revisión biográfica», Historia, n. ${ }^{\circ}$ 40, vol. 1, Santiago, 2007, pp. 91-128.

43. Gazmuri, Cristián, La historiografía chilena ..., cit., p. 197. 
to Edwards y Francisco Antonio Encina». ${ }^{44}$ Se desvirtuaría, de esta forma, la tarea del historiador, que no puede ser otra que comprender y explicar el pasado.

En la segunda mitad del siglo Xx, fue original e influyente la perspectiva de Julio Heise González. Heise fue Decano de la Facultad de Filosofía y Humanidades de la Universidad de Chile y dedicó varios libros a la historia institucional de Chile. Es conocida su reivindicación del llamado período pseudoparlamentario, sobre el cual sostiene que se inició en 1861, y no luego de la caída del presidente Balmaceda, según la visión tradicional.

En varios trabajos se abocó a la época en estudio. En su libro Años de formación y aprendizaje políticos, 1810-1833, inserta la década de los '20 dentro del proceso mayor y coetáneo de consolidación de la independencia y el Estado chileno..$^{45} \mathrm{La}$ «organización de la república, un auténtico aprendizaje político», según reza el epígrafe de la Cuarta Parte del libro mencionado, incluye El Gobierno de O'Higgins y La Constitución de 1833, como capítulos primero y último; de manera que ambos quedan incluidos dentro de la periodificación que propone. Se trataría de un proceso gradual, siempre en ascenso, en que cada etapa resulta un avance necesario. Rechazando la tesis del caos, en efecto, propone una interpretación de la época como una de aprendizaje ineludible y positivo para consolidar la posterior administración conservadora. Así, expresa: «El éxito de Portales es inconcebible sin la consideración del lento y difícil aprendizaje político que debió realizar la clase dirigente chilena entre los años 1810-1830».46

Una valoración positiva para una época compleja que se refuerza en la comparación, que efectúa del desarrollo institucional chileno con los eventos contemporáneos de los países vecinos y, sobre todo, con el de Estados europeos como España, Francia o Suiza. Concluye exaltando las realizaciones de esta etapa organizativa, en diversos planos.

Analiza el concepto de «anarquía política» con una mirada particular. Cada generación, sostiene, renueva la interpretación de un mismo proceso histórico; nadie, no obstante, se ha ocupado de precisar el contenido y caracteres del período. Va todavía más allá al afirmar que el problema aún se ha enfocado con «ánimo mezquino y con criterio anticientífico». ${ }^{47}$ Para los historiadores conservadores, los años de 1823 a 1830 fueron una época de retroceso y decadencia irremediables. Los liberales, aunque por caminos diferentes, arribaban a conclusiones parecidas. Incurriendo en un progresismo y racionalismo forzados, ajenos a la realidad concreta, rechazando la herencia hispana, condenaban también los eventos ocurridos tras la caída de O’Higgins. Su análisis, concluye, estaba teñido de espíritu partidista.

Distingue la anarquía, caracterizada por la falta de todo gobierno en un Estado, desorden y autoridades arbitrarias, de la simple crisis. Esta consistiría en la «alteración vital

44. Villalobos, Sergio, «Sugerencias para un enfoque del siglo XIX», Colección de estudios CIEPLAN, n. ${ }^{\circ} 12$, Santiago, 1984 , pp. 9-36.

45. Heise González, Julio, Años de formación y aprendizaje político 1810-1833, Santiago, Editorial Universitaria, 1978.

46. Heise González, Julio, 150 años de evolución institucional, Santiago Andrés, Bello, 1960, p. 29.

47. Heise González, Julio, Años de formación ..., cit., p. 11. 
del sistema de convicciones tradicionales que es substituido por otro». Es lo que habría ocurrido en Chile y destina largas páginas a probarlo. La ausencia de caudillismo y de militarismo, el sentido de la juridicidad, la incipiente formación de grupos políticos, la existencia de prensa y oposición, son elementos que alejarían el caso chileno de la anarquía o la dictadura. Lo mismo la «perfecta armonía social», que se tradujo en ausencia de pugnas raciales o de clases, así como de revoluciones sangrientas. Incluso las ideologías, añade en un su tono siempre optimista, «como instrumentos de motivación política», fueron elementos decisivos en la organización de la república.

Las graves dificultades que atravesó el país habrían sido la consecuencia natural del «dramático cambio espiritual» que produjo el «brusco rompimiento del equilibrio colonial». Las fuerzas antirrepublicanas conservaban su prestigio y capacidad de resistencia; subsistían también los hábitos coloniales. Era inevitable esa «desorientación vital, esa inquietud germinal». Dificultades todavía mayores habían experimentado las sociedades europeas, desgarradas por la Revolución Francesa, en su tránsito hacia la democracia burguesa. La llamada «anarquía hispanoamericana», concluye, no fue otra cosa que un estado de desequilibrio político y una afanosa búsqueda de una estructura institucional adecuada. A demostrarlo dedica la obra que mencionamos y también su libro previo 150 años de evolución institucional. ${ }^{48}$

En verdad, su análisis madura y se va sofisticando con los años. En sus tempranos Apuntes de Clases, de 1959,49 ya insinuaba que «la lucha por la organización del Estado», revistió en Chile características peculiares. Se habría tratado de un período «en el fondo y en su conjunto, fecundo», del cual resultó «un progreso general y prometedor». Lo explica en torno a cuatro factores: El cambio brusco de las instituciones tradicionales, que dejaron de corresponder al medio, provocando complejos ajustes; la postración económica y la pobreza, provocada por la guerra, que exigió reconstruir las fuentes de riquezas destruidas, pero también crear otras nuevas. En tercer término, la «incultura», que no solo afectaba a las masas populares, sino también se extendía a la ausencia de educación política en las clases altas; sin tradición política, la libertad degeneró en desorden y luego en la dictadura y el caudillismo. Finalmente, el «falso concepto de la ley», esto es, la inadecuación de las normas en función de la realidad social que pretende regir, era también causa de las dificultades. Ilustraba el punto, con la temprana adopción de un sistema representativo, que daba «al pueblo una participación directa en el gobierno, sin que existiera posibilidad alguna de realización».50

En su obra de madurez, Años de formación..., aparecida en 1978, profundizó en su visión, planteando una periodificación de los años de la anarquía. El hilo conductor es la idea de un «aprendizaje político», en el cual el gobierno de Bernardo O'Higgins habría sido la primera etapa. Le siguió una reacción antiautoritaria y descentralizadora, de in-

48. Heise González, Julio, 150 años de evolución..., cit.

49. Heise González, Julio, «Colección de Apuntes de Clases n. ${ }^{\circ}$ 3», Historia Constitucional de Chile, Santiago, Universidad de Chile, 1959, pp. 45 y ss.

50. Heise González, Julio, Años de formación ..., cit., p. 64. 
tensidad creciente; hasta que, durante el gobierno de Francisco Antonio Pinto, se inicia la «reacción centralizadora». La reacción autoritaria, quinta etapa de la organización de la república, ocurre con la llegada de Portales al poder.

Entre las reminiscencias indianas a superar, destaca el «asambleismo municipalista», que resulta del espíritu hispano-colonial. Este se expresa tanto en la organización de asambleas legislativas fuertes, que coartan la acción del ejecutivo, como en la actuación de las asambleas provinciales de Coquimbo, Santiago y Concepción frente al Gobierno central. Serían dos caras del mismo fenómeno. Lo califica de «abundante fuente de anarquía».

Una anarquía que, en el caso de Chile, estuvo exento de dictaduras, caudillismo, cuartelazos o militarismo. ¿Qué explica tanta moderación? Para Heise, desde el punto de vista social, la homogeneidad de la población, «con muy escasa proporción de indígenas y sin aporte alguno de sangre negra», evitó la pugna racial. Aunque la afirmación es errada en términos fácticos, es efectivo que los conflictos raciales no definieron la evolución política. A continuación añade que la lucha por la organización del Estado fue protagonizada por una aristocracia muy cohesionada. «Es ella la que en verdad hace la historia», afirma. Ni siquiera se observaron graves conflictos entre mineros y comerciantes, como ocurrió en México, o entre estos y los ganaderos, como en el Río de la Plata. ${ }^{51}$ La ausencia de líderes o masas populares, además, sería uno de los rasgos más originales de la evolución chilena en el siglo XIX. El autor es tan tajante, como irredimible en su mirada finalmente optimista:

En Chile, el avance democrático se realizó desde arriba hacia abajo. Todas las reformas liberales serán obra de la aristocracia, obra de una élite, desde la cual, como desde una cumbre, descendían las reformas democráticas hasta los estratos inferiores. Nada germinaba entonces en la llanura; todo bajaba de la cima: la educación, la democracia, las libertades, el sufragio. Todo era patrimonio exclusivo de una élite que, a manera de concesión graciosa, irradiaba de vez en cuando hacia el pueblo algunas conquistas de ese liberalismo democrático celosamente conservado y administrado por ella. Y es interesante comprobar que en esta forma logró Chile una estructura democrática perfectamente orgánica y, como tal, de singular solidez. ${ }^{52}$

Es interesante que Heise considera las tensiones provinciales como una explicación al desorden propio de la época. Lo asocia al «centralismo» de la capital, tanto como al «localismo» de las provincias. Coincide con Luis Vitale, aunque sin el sesgo marxista, en asignarle importancia. Al interpretarlo solo como una rémora del Antiguo Régimen, no obstante, propio de la inexperiencia política, falla en captar la fuerza de los proyectos alternativos que, en el caso de varios países vecinos, desembocaron en la instauración del

51. Promis Díaz, Fernando, reseña del libro Años de formación y aprendizaje político. 1810-1833, de Julio Heise, Editorial Universitaria, Santiago, 1978, Revista de Historia, Universidad de Concepción, año III, volumen III (segunda época), n. ${ }^{\circ}$ 3, Concepción, 1978, pp. 65-66.

52. Heise González, Julio, Años de formación y aprendizaje político 1810-1833, Editorial Universitaria, Santiago, 1978, p. 111. 
federalismo. Desconoce, asimismo, los avances liberales, que luego fueron revertidos, como acciones inoportunas, improvisadas, y no como expresiones, en cambio, de un liberalismo temprano, que terminaría abortado.

\section{La perspectiva de la historia social}

Aproximaciones más modernas, aunque menos lapidarias en su visión de la década, anticipan debates y divisiones partidistas que resultan prematuros para una época sin instituciones ni un espacio público «nacional» consolidados. Se reconoce correctamente, según veremos, que se trata de un período formativo, una época «líquida» en cuanto a grupos e ideologías. No se aquilata, sin embargo, la radical diferencia de los proyectos alternativos en juego, a nivel territorial, ni las dimensiones sociales y materiales de los conflictos. Todo se reduce a diferencias políticas.

Son justamente los aspectos que relevan los textos de Luis Vitale, profundizados, en tiempos más recientes, por Gabriel Salazar. Nos referimos a la lucha social y la «rebelión de las provincias», frente al orden centralizado que pretendía imponer la oligarquía de la provincia central. Aunque la división social que plantea el primer autor, producto de su aproximación marxista al período, resulta un poco forzada, acierta en identificar una arista mencionada, pero no valorizada por los autores tradicionales.

Desde el campo de la historia social, la contribución más significativa a la historia del período, se debe a la pluma de Luis Vitale. En su Interpretación Marxista de la Historia de Chile plantea derechamente que el problema central, que marca el desarrollo político de la década de 1820, son las tensiones regionales. Este habría sido el factor decisivo en la caída de O'Higgins y en las luchas y debates posteriores. De ahí que titula al período de «la rebelión de las provincias». ${ }^{53}$

La mayoría de los autores sindican a esta como a una etapa de caos, mas sin ofrecer una explicación a la rotativa de gobiernos y al desorden, lo que conduce a aceptar la noción de anarquía. No sería una imputación inocente, según Vitale. Lo que realmente se busca descalificar son las luchas sociales del momento, consistentes en la abolición de los mayorazgos, expropiación de ciertos bienes de la Iglesia Católica y la participación política de los sectores populares, como el artesanado. Y el empeño más importante de todos: combatir el centralismo de la capital, reivindicando los derechos de las provincias. ${ }^{54}$

A la «deformación histórica deliberada» de los autores conservadores, debe añadirse la incapacidad de los liberales de ir más allá de la superestructura política. De manera mecánica trasladan los debates de la segunda mitad del siglo XIX a los años 1823-1830, actitud que les impide captar los problemas de fondo. Avanzando ya el siglo XX, Alberto

53. Vitale, Luis, Interpretación Marxista de la Historia de Chile. La independencia política, la rebelión de las provincias y los decenios de la burguesía comercial y terrateniente, Santiago, Prensa Latinoamericana S.A., 1971, p. 59.

54. Vitale, Luis, Interpretación Marxista..., cit., p. 89. 
Edwards y Francisco Encina, con gruesos adjetivos —Estado «sin forma», «turbulentos», «desconformados cerebrales»— habrían terminado de cubrir de baldón la antes llamada «era de los pipiolos».

¿Cómo se explica, en la mirada de Vitale, el aparente caos político? No desconoce que se trató de una fase de extrema inestabilidad política, originada en la Revolución de 1810. El término de la guerra y, con ello del enemigo común, abrió cauce a las diferencias entre sectores de la burguesía criolla, ahora enfrentadas por el control del Estado.

Al término de la guerra, hizo crisis el frente único de carácter político que habían formado, a pesar de sus diferencias, los distintos sectores para enfrentar al ejército español. Se abrió entonces un período de lucha entre las fracciones burguesas por el control del aparato del Estado. La principal disputa, a juicio del autor, fue la rebelión de las provincias. Consecuente con su análisis marxista, asigna al conflicto, más que un sentido geopolítico, una lectura de pugna de intereses de clase. «Era la expresión aguda, en efecto, de la protesta de sectores burgueses provincianos postergados por el centralismo de la capital, cuyos gobiernos actuaban como representantes de la burguesía santiaguina».55

De manera que, para Vitale, la participación activa de las provincias en la política nacional fue el fenómeno más relevante del período. Fue también la tónica en varios otros países de América. Tuvo por base la división tradicional de Chile en tres bloques regionales: Coquimbo, Santiago y Concepción. En estos años, concluye, «no hubo acontecimiento político de importancia donde las provincias no jugaran un papel decisivo».

Las disputas regionales tendrían su corolario ideológico, al decir de Byron Asken, quien suscribe las tesis de Vitale. Se expresan en la configuración de dos proyectos políticos en el seno de las élites: «el conservador o pelucón, partidario de un Estado centralista, autoritario y librecambista, y el liberal o pipiolo, defensor de un Estado con una organización más descentralizada, democrática y promotora de la producción nacional». El período de la «Anarquía» sería, por lo tanto, la más aguda expresión de las tensiones entre los distintos pueblos soberanos, condición que atribuye a las provincias..$^{56}$

Medio siglo más tarde, una tesis renovada ahonda en esta perspectiva. Para Gabriel Salazar, el tiempo que transcurre entre 1810 y 1837, es decir, entre la Primera Junta de Gobierno y la muerte de Diego Portales, sería el «tiempo-madre de la historia política chilena», el período de «la fundación del Estado y la Política». En ese largo cuarto de siglo se definió el panteón de héroes nacionales y de valores públicos; fue el tiempo épico en que se definió el «alma nacional». ${ }^{57}$ La primera parte, sin embargo, que corresponde a la lucha militar por la independencia, ha recibido mucha mayor glorificación que la segunda, que representaría la subsiguiente «lucha política por la democracia republicana». La lucha por la emancipación es encarnada en el régimen militarizado de O'Higgins,

55. Vitale, Luis, Interpretación Marxista..., cit., p. 95.

56. Asken Montes, Byron S., «Autonomía y centralismo: la configuración del Estado y la Nación chilena (1823-1830)», Naveg@mérica. Revista electrónica editada por la Asociación Española de Americanistas, n. ${ }^{\circ}$ 16, Murcia, 2016, p. 2.

57. Salazar, Gabriel, Construcción de Estado..., cit., p. 22. 
promotor del orden; en tanto que «el movimiento democrático que impulsaron después de 1822 la mayoría liberal, los pueblos de provincia y el general Ramón Freire», aparece ensombrecido en las páginas de la historia tradicional.

Este personaje en particular, en la misma medida que la actuación de Bernardo O’Higgins es denostada, aparece relevado de manera inusitada. Dice Salazar, en efecto, que Freire

...fue, ante todo, un militar con conciencia ciudadana y un liberal demócrata permanentemente preocupado de que la soberanía popular tuviera la mejor oportunidad para ejercer por sí misma su poder constituyente. No ha habido militar en toda la historia de Chile que haya actuado con semejante ética política. ${ }^{58}$

Con estas palabras, se erige, por desgracia no con suficiente justificación fáctica - la Historia General de Chile, de Barros Arana y las Sesiones de los Cuerpos Legislativos, confiesa, son sus fuentes principales-, en el mayor defensor del general penquista que lideró y abandonó el gobierno cuatro veces, en el relativamente breve período que comentamos. Es la polaridad inversa de la historiografía de la anarquía, atrapada en las mirada cruzadas del pasado y el presente. Cuestionando, en efecto, en clave actual, las acciones de los hombres de 1830, se pregunta: «¿se justifica admirar, reproducir y mantener en vigencia todavía hoy los métodos políticos que Portales, según se nos hace creer, inmortalizó después de la sangrienta batalla de Lircay?».

Siguiendo la lógica de Luis Vitale, aunque sin señalarlo, la obra de Salazar centra en «la revolución de los pueblos» su análisis del período. Es consistente con el argumento del llamado derecho de los pueblos, con que está construido su texto. Afirma, en breve, que este se basa en la tradición foral transplantada por los españoles a América, la cual fue conculcada, con el advenimiento de la república, por las nuevas autoridades revolucionarias. Estas perseguían, siguiendo una agenda liberal a la manera francesa, que se gobernara centralizadamente al Estado, desde la capital Santiago, subordinando al resto de las ciudades y provincias del país, prescindiendo de sus tradiciones, fueros y prerrogativas propias. El análisis incluye una no bien justificada separación entre los intereses mercantilistas de la capital y los productivistas de los provincianos. Afirma, además, la existencia de una conspiración permanente por parte de una élite extranjerizante y mercantilista localizada principalmente en Santiago y Valparaíso, dispuesta a destruir a una supuesta clase de pequeños productores que se identificaban casi en forma perfecta con los miembros de los cabildos, y que sostenían un modelo económico rayano en la autarquía.

El valor de la tesis de Salazar es el rescate de la «tradicional democracia cabildante», como una fuerza y una legitimidad alternativa que se proyecta desde tiempos coloniales.

58. Salazar, Gabriel, Construcción de Estado..., cit., p. 27. Comenta, al efecto, Cristóbal García-Huidobro, en su reseña del libro de G. Salazar: «Creo que al igual que ocurre usualmente en el mundo de los biógrafos, Salazar se «enamoró» de su personaje y terminó exagerando las bondades del mismo» García-Huidobro B., Cristóbal, Reseña del libro «Construcción de Estado en Chile (1800-1837)», Historia, n. ${ }^{\circ}$ 40, vol. I, Santiago, 2007, pp. 194-198. 
La propia abdicación del Director Supremo habría sido provocada «por una cadena de asambleas populares» que, de sur a norte del país, reclamaron para los pueblos la soberanía y el poder para elegir gobernantes y congresos nacionales. ${ }^{59}$ Salazar llama al proceso «la revolución de "los pueblos" (1822-1823)» y trata los años siguientes como un proceso revolucionario y contrarrevolucionario. Las provincias encarnarían a los productores, artesanos y pequeños empresarios, por oposición a los grandes mercaderes y latifundistas que se concentraban en Santiago. Como en otra parte hemos escrito, si bien hay algo de verdad en esta asociación de grupos e intereses, no siempre es fiel a la realidad, como ya demostramos para el caso de Concepción, en la coyuntura de 1810. Las profundas razones culturales, históricas y geográficas en que se funda el regionalismo, así como una lectura más atenta del influjo del liberalismo en la época en estudio, nos llaman a evitar este reduccionismo materialista. ${ }^{60}$

\section{Miradas contemporáneas}

Entre las voces críticas a la actuación de Diego Portales y su supuesta sobrevaloración por la historiografía conservadora, destaca Sergio Villalobos y su Portales, una falsificación histórica. ${ }^{61} \mathrm{El}$ libro, publicado en 1989, con múltiples reediciones, aparece en un contexto de rechazo de su autor al gobierno militar y al uso político de la figura del Ministro mártir. ${ }^{62}$ Para Villalobos, es «evidente» que los historiadores conservadores exageraron los males de la época para realzar el período de Portales. Aún los acusa, con directa alusión a Edwards y Encina, de denigrarla porque no coincide con sus ideas, desvirtuando de paso la tarea del historiador. La realidad, expone, habría sido muy distinta y se explica por las complejas circunstancias que provocaron las guerras de emancipación.

Su visión del período puede extraerse de diversos libros e historias generales de que es autor. ${ }^{63}$ Nos basaremos en un texto breve referido a los enfoques con que debe estudiarse el siglo XIX, hace una aproximación historiográfica. ${ }^{64}$ Para el autor de El comercio y la crisis colonial, la «aparente anarquía inicial» es consecuencia del descalabro económico que provocaron el financiamiento de la guerra y la destrucción asociada a los combates. A lo anterior se suma la inexperiencia en autogobierno y representación soberana de los antiguos súbditos chilenos de la monarquía hispana. República, constitución y dere-

59. Salazar, Gabriel, Construcción de Estado..., cit., p. 178.

60. Cartes Montroy, Armando, «Un gobierno de los pueblos...» Relaciones provinciales en la independencia de Chile, Valparaíso, Ediciones Universitarias de Valparaíso, 2014, p. 237.

61. Villalobos, Sergio, Portales, una falsificación histórica, Santiago, Editorial Universitaria, 1989.

62. Cf. Cartes, Armando, «¿Estadista "en forma...», cit.

63. Cf. Villalobos, Sergio, Historia de los Chilenos, Santiago, Editorial Taurus, 2006-2010; Historia del pueblo chileno, Santiago, Zigzag, 1983; y con Osvaldo Silva, Fernando Silva y Patricio Estellé, Historia de Chile, Santiago, Editorial Universitaria, 2006.

64. Villalobos, Sergio, «Sugerencias para...», cit., reed. en: Villalobos, Sergio, Estudios y ensayos en torno a la historia de Chile, Santiago, Editorial Universitaria, 2010. 
chos ciudadanos «eran conceptos nuevos en el mundo y mucho más en el rincón olvidado de Chile». ${ }^{65}$

Era inevitable que las dificultades del momento impidieran la organización de un gobierno efectivo. El descontento de los militares agravó la situación. Licenciados de las campañas de la Independencia o con sus rentas rebajadas por las estrecheces del erario, protagonizaron conspiraciones y levantamientos. Pero también hubo grandes avances, que Villalobos destaca. La Independencia misma se consolida, material y jurídicamente, durante esta década. La república se instala como el régimen perdurable y hay avances significativos en materia educacional, constitucional y de organización de la hacienda pública. En definitiva, lejos de la anarquía, para Villalobos, en los años veinte se dieron pasos importantes para asegurar el destino del país.

La década en estudio fue también observada por autores extranjeros. Estos miran la evolución política chilena con mayor referencia al contexto americano, así como con los sesgos de su propia formación. Es el caso del historiador inglés Simon Collier, que en 1967 publica una obra que ha sobrevivido al tiempo, al punto de merecer dos traducciones. $^{66}$

Plantea que, a nivel general, la década de 1820 fue compleja y vio una reacción liberal, frente a los militares autoritarios que habían hecho la revolución. Un sentimiento federalista o, al menos, anticentralista, recorrió el continente; todo lo cual se refleja en las disputas que vivió la Gran Colombia, la incipiente Argentina o el propio Chile. Para el fin de la década, la utopía liberal empezaba a resquebrajarse, dando paso a una reacción conservadora. En algunos países llevó a la anarquía, interrumpida por breves tiranías; en otros, a largas dictaduras personalistas. Solo Chile, al decir de Collier, habría podido sustraerse a este patrón. Al establecer una autoridad fuerte, aunque impersonal, el país preparó el camino para el futuro gobierno constitucional y una «genuina tradición democrática». ${ }^{67}$ Obra que atribuye fundamentalmente a un hombre, Diego Portales y que habría empezado a gestarse con el colapso del gobierno liberal, en la primavera de 1829.

En una obra posterior, aparecida en Chile en 2008, reconoce los avances en la historiografía sobre el período, en los treinta años precedentes, relativos a las décadas que siguieron a la Independencia. ${ }^{68}$ Se mantiene, no obstante, a su juicio, una carencia: «No existe, dice, en la historiografía chilena y menos aún en la producida fuera de Chile, una interpretación política general acerca de la república temprana que pueda ser catalogada como 'tradicional'». Los textos de los autores clásicos aparecen como fragmentarios y, al igual que los emanados de autores posteriores, estarían marcados por las diferencias ideológicas, que han marcado la historia —y la historiografía - política nacional. ${ }^{69}$

65. Ibidem, p. 260.

66. Collier, Simon, Ideas and politics of Chilean independence 1808-1833, Cambridge, Cambridge University Press, 1967; obra reeditada, en español, en 1977 y 2016.

67. Collier, Simon, Ideas and politics..., cit., p. 323.

68. Collier, Simon, La construcción de una República. Política e ideas (1830-1865), Santiago, Ediciones PUC de Chile, 2008, p. 114.

69. Collier abordó el tema en «The Historiography of Chile's "Portalian" Period», Hispanic American 
El tiempo que se inicia en 1823, para Collier, será testigo de «la impresionante embestida del liberalismo decimonónico», que influyó con fuerza creciente en la clase alta chilena, sin importar su afiliación política, a medida que fue creciendo en riqueza y sofisticación. ${ }^{70}$

El historiador inglés Leslie Bethell, por su parte, explica la crisis chilena de 1823 por razones ideológicas, pero también personales. Así, Ramón Freire quería alejarse del autoritarismo de O'Higgins y el carisma de José Miguel Infante fue, en buena medida, responsable del «momento federal» que vivió el país. ${ }^{71} \mathrm{La}$ ola liberal, que quería levantar una república sobre las ruinas de la Colonia, influyó en la radicalidad inicial de los discursos. La «anarquía» del período, con todo, ha sido exagerada a menudo por los historiadores chilenos, asevera Bethell, pues fue muy limitada, comparada con la situación de los países vecinos. Ya empezaba a conjurarse en tiempos de la presidencia de Francisco Antonio Pinto (1827-1829) y gracias a una nueva Constitución (1828) bien estructurada. Pero ya era tarde para contener la reacción conservadora contra el reformismo liberal, que se había hecho odioso por su discurso antiaristocrático y su sesgo anticlerical. Todo lo cual degeneró en una guerra civil, que condujo al régimen conservador que luego se impuso.

La mirada del investigador norteamericano especialista en Chile, Brian Loveman, no se aleja mucho de lo expuesto por Collier. La «anarquía» fue una mezcla de consignas, personajes e ideologías, acompañadas de una confusa sucesión de congresos, asambleas, directores supremos y rebeliones militares. «Superficiales experimentos» de liberalismo y federalismo, salpicados de anticlericalismo, entraron en conflicto con las prácticas administrativas y la estructura social y económica tradicionales de Chile. ${ }^{72}$ Para Loveman, los esquemas descentralizadores copiados del federalismo norteamericano no correspondían a la realidad del «capitalismo hispánico» del Chile postindependencia. Se alejaban de la realidad política e intensificaron los conflictos regionales, haciendo ilusorio el gobierno nacional efectivo.

Loveman, advierte, en todo caso, que la actividad política se desarrollaba en círculos muy estrechos. La legislación liberal y las sucesivas constituciones, con su lenguaje de federalismo o derechos inalienables, era ajena a la tradición de «despotismo pragmático y benevolente», de los oficiales reales. No había experiencia de involucramiento del «pueblo» en la administración o la legislatura; de ahí que movimientos personalistas, como los de O’Higgins, Freire o Carrera, fueran copando el espacio. Faltaba todavía mucho tiempo para la instalación de un sistema político multipartidista, con claridad ideológica y consolidación institucional.

Historical Review, vol. 57, n. ${ }^{\circ}$ 4, Washington D.C., 1977, pp. 666-669. Consultar igualmente Cartes, Armando, «¿stadista 'en forma...», cit.

70. Collier, Simon, La construcción ..., cit., p. 26.

71. Bethel, Leslie (ed.), Chile since independence, Cambridge, Cambridge University Press, 1993, pp. 2-3.

72. Loveman, Brian, Chile: The Legacy of Hispanic Capitalism, Nueva York, Oxford University Press, 1988, p. 107. 
La Constitución de 1828, a pesar de su pacífica discusión y sanción, produjo inconformidad en varios sectores. Los federales quedaron frustrados por el abandono de sus propuestas, los conservadores veían en el texto otra utopía ideológica importada y la vieja aristocracia, enfrentada a la abolición de los mayorazgos y los conflictos clericales, se situó en una férrea oposición. Nuevamente estalla la guerra civil y es la imposición del gobierno pelucón su inevitable corolario.

En fin, las miradas más recientes se mueven entre la visión del período como uno de ensayos y una moderada anarquía. Así, para Javier Infante, forma parte de la etapa de la consolidación del régimen republicano. De ahí que se acercaría más a un tiempo fundacional que a uno anárquico. ${ }^{73}$ Se caracterizó por el debate de facciones, antes inhibido por el autoritarismo del régimen de O'Higgins. Ahora la deliberación política llegaba a las calles y se integraban otros actores, como federalistas, pipiolos y provincianos. La prensa azuzaba los debates y se sucedieron los ensayos constitucionales. Pero detrás de la aparente crisis, dice Infante, compartiendo el optimismo — excesivo, a nuestro juiciode Julio Heise, «los conceptos de racionalismo jurídico, de liberalismo e individualismo políticos, de derecho natural y de soberanía absoluta imperan en toda plenitud». En síntesis, una época de avances, cuyos trastornos parecen haberse desvanecido en la distancia.

Más templado es el juicio de Alejandro San Francisco, escribiendo en el año del Bicentenario, quien, bajo el epígrafe ambivalente de «Anarquía y aprendizaje político (1823-1830)», resume los rasgos centrales de la época. ${ }^{74}$ Luego de pasar revista a los autores que la juzgan como anarquía - Alberto Edwards y Francisco Antonio Encina, por ejemplo- y los que la ven como un período de formación y aprendizaje políticos, tales como Donoso, Heise y Collier, concluye que ambas situaciones coexistieron: «hubo ensayos de organización republicana con algunas instituciones que pervivieron y una clara anarquía política». La cual se refleja en los irregulares mecanismos de traspaso del mando y, en general, la desorganización del país, que se reflejara en numerosas administraciones y constituciones.

Por último, consignemos que si anarquía y aprendizaje fueron el sello de la época, en la tradición historiográfica de Chile, el sentido común ha tendido al repudio de los espíritus anárquicos, revoltosos o perturbadores. De ahí el desafecto a los momentos y a los personajes que encarnan — real o simbólicamente- estos rasgos. En los diagnósticos de diversas épocas, dice Alfredo Jocelyn-Holt, «vemos este afán de constituir el desorden en excepción, erigiendo el orden en la columna vertebral de nuestro ser nacional»; única forma de confirmar nuestra autoimagen de país «excepcional». ${ }^{75}$ Una característica de

73. Infante, Francisco Javier, Autonomía, independencia y república en Chile, 1810-1828, Santiago, Centro de Estudios Bicentenario, 2014, p. 223.

74. San Francisco, Alejandro, «La vida política», en Fermandois, Joaquín (dir.), Chile, Crisis imperial e independencia, tomo 1, Lima, 1808/1830, Taurus, 2010.

75. Jocelyn-Holt Letelier, Alfredo, El peso de la noche, nuestra frágil fortaleza histórica, Santiago, Planeta/ Ariel, 1998, pp. 183-184. 
los estudios históricos que también explica que la mirada crítica hacia la época se haya vuelto canónica.

\section{Conclusiones}

En años recientes, puede apreciarse que si bien Diego Portales, su régimen y su figura, siguen siendo un campo de batalla historiográfico, no ocurre ya lo mismo con la década previa. Se ha superado la calificación de «anarquía», por su sesgo político conservador y peyorativo. ${ }^{76}$ Aunque se reconoce el desgobierno, la crisis económica y la dislocación que produjo el bandolerismo, sobre todo en el sur, es claro que la violencia y la anulación de las libertades no alcanzó la intensidad de los países vecinos. Participó Chile, en cambio, de la reacción conservadora que caracterizó a la tercera década de las revoluciones americanas. Se trató de un proceso de organización que trajo el desgobierno extremo, y luego un orden construido a un alto precio. En definitiva, un aprendizaje inevitable y necesario, en la transición hacia un Chile republicano.

Se encuentra pendiente, a nuestro juicio, rescatar el carácter fundacional de esta década, en dimensiones de orden ideológico, político e institucional, pero también económico y social, del Chile que se construye a lo largo del siglo XIX. También debe recuperarse el rol clave que jugaron las provincias, desde sus asambleas y sus líderes en los debates y combates del período. Lo anterior no solo como expresión del caudillismo local o de «celos provinciales» (Encina), sino como manifestación de un modelo alternativo de Estado, triunfante allende la cordillera y en varios otras naciones americanas, aunque en Chile resultó derrotado.

En los últimos años se ha abierto paso, entre los historiadores latinoamericanistas, la idea de que la década de 1820 fue un tiempo de exploración, experimentación e innovación. ${ }^{77}$ Se requiere, en consecuencia, analizar la época en el marco hispanoamericano, no para reiterar el viejo discurso de la excepcionalidad, sino para mirar a Chile en el campo más amplio de los desafíos comunes que enfrentaron las nuevas naciones. La vacatio regis y la crisis institucional, la expansión del liberalismo, la modernización capitalista o la construcción de identidades nacionales, son cuestiones sobre las que una visión comparada —o entrecruzada- puede arrojar muchas luces. ${ }^{78}$

76. Así, una obra reciente, curiosamente, se sustrae al debate. En 1808 Historia de la república de Chile, volumen I, la Tercera Parte se denomina «La consolidación de la independencia», omitiendo cualquier referencia especial referencia al período: Silva Vargas, Fernando y Aldunate, Carlos (eds.), 1808 Historia de la república de Chile, volumen I, Santiago, Zig-Zag, 2013.

77. Crow, Joanna, Introducción al dossier «New Perspectives on Political Ideas and Practices in Post-Independence Chile (1818-1830)», Bulletin of Latin American Research, vol. 36, no. 3, Oxford, 2017, pp. $283-284$. El dossier contiene trabajos sobre la cuestión mapuche, la influencia del liberalismo, los cambios económicos y prácticas educativas, los que en conjunto señalan nuevos derroteros de investigación.

78. Cf. Cartes Montory, Armando, «Nación y Federación en Chile y el Río de la Plata», en Cáceres Muñoz, Juan y Jaime Vito Paredes (eds.), Pensar la historia. Teoría, análisis y prácticas. Homenaje a Eduardo Cavieres Figueroa, Valparaíso, Ediciones Universitarias de Valparaíso, 2016. 
El profundo cambio de la cultura política, el republicanismo en ciernes, el rol de la prensa y el espacio público, en fin, se comprenden mejor en la mirada ampliada de los procesos comparados. Los interrogantes y las disyuntivas eran las mismas para Chile y otros países; pero las respuestas fueron diferentes. El caudillismo, la dictadura y las guerras civiles fueron en Chile más breves y acotadas. La homogeneidad de la élite que condujo el proceso y el territorio reducido, entre varios factores que hemos revisado, favorecieron la más temprana construcción de un orden republicano efectivo. De manera que si hubo alguna «excepcionalidad» en el caso chileno, fue más en las soluciones que en los desafíos.

En definitiva, parece imponerse una mirada más equilibrada de la situación chilena en el contexto americano. Se echa de menos todavía, no obstante, una comprensión profunda de los proyectos alternativos en juego, más allá de los intereses de grupos y las ambiciones personales. Está pendiente, igualmente, una valoración del cariz fundacional de esa década, en la adopción de definiciones que han caracterizado el republicanismo chileno.

\section{Bibliografía}

Alemparte, Julio, Carrera y Freire, forjadores de la República, Santiago, Editorial Nascimento, 1963. Amunátegui Solar, Domingo, Pipiolos y Pelucones, Santiago, Universidad de Chile, 1939.

Asken Montes, Byron S., «Autonomía y centralismo: la configuración del Estado y la Nación chilena (1823-1830)», Naveg@mérica. Revista electrónica editada por la Asociación Española de Americanistas, n. ${ }^{\circ}$ 16, Murcia, 2016.

Baradit, Jorge, Historia secreta de Chile 2, Santiago, Editorial PRH (Sudamericana), 2016.

Bédarida, François, «Definición, método y práctica de la Historia del Tiempo Presente», Cuadernos de Historia Contemporánea, n. ${ }^{\circ}$ 20, Madrid, 1998, pp. 19-27.

Bethel, Leslie (ed.), Chile since independence, Cambridge, Cambridge University Press, 1993.

Bravo Lira, Bernardino, El absolutismo ilustrado en Hispanoamérica, Chile (1760-1860), Editorial Universitaria, Santiago, 1992.

Campos Harriet, Fernando, Historia Constitucional de Chile, Santiago, Editorial Jurídica de Chile, 1992, séptima edición.

Cartes M., Armando, «¿Estadista «en forma» o falsificación histórica? Diego Portales ante la historiografía chilena», en: Concepción y el Bicentenario, Departamento de Historia y Ciencias Sociales Universidad de Concepción, junio de 2012.

—, «Un gobierno de los pueblos...» Relaciones provinciales en la independencia de Chile, Valparaíso, Ediciones Universitarias de Valparaíso, 2014.

—, «Nación y Federación en Chile y el Río de la Plata», en Cáceres Muñoz, Juan y Vito Paredes, Jaime (eds.), Pensar la historia. Teoría, análisis y prácticas. Homenaje a Eduardo Cavieres Figueroa, Valparaíso, Ediciones Universitarias de Valparaíso, 2016, pp. 235-255.

Chartier, Roger, El mundo como representación. Historia cultural: entre práctica y representación, Barcelona, Gedisa, 1996.

Collier, Simon, Ideas and politics of Chilean independence 1808-1833, Cambridge, Cambridge University Press, 1967.

—, «The Historiography of Chile's "Portalian" Period», Hispanic American Historical Review, vol. 57, n. ${ }^{\circ}$, Washington D.C., 1977, pp. 660-690. 
—, La construcción de una República. Política e ideas (1830-1865), Santiago, Ediciones PUC de Chile, 2008.

— y Sater, William, A History of Chile, 1808-1994, Cambridge, Cambridge University Press, 1996.

Crow, Joanna, Introducción al dossier «New Perspectives on Political Ideas and Practices in PostIndependence Chile (1818-1830)», Bulletin of Latin American Research, vol. 36, n. ${ }^{\circ}$ 3, Oxford, 2017, pp. 283-284.

Del Solar, Felipe y Pérez, Andrés, Anarquistas, presencia libertaria en Chile, Santiago, Ril Editores, 2008.

Donoso, Ricardo, Las ideas políticas en Chile, México D.F., Fondo de Cultura Económica, México, 1. ${ }^{\text {a }}$ edición, 1946.

Edwards Vives, Alberto, Bosquejo histórico de los partidos políticos chilenos, Santiago, Guillermo Miranda Editor, Imprenta Mejías, 1903.

—, La organización política de Chile, Santiago, Editorial del Pacífico, 1943.

—, La Fronda aristocrática, Santiago, Editorial del Pacífico S.A., 1952.

Edwards Vives, Alberto y Eduardo Frei Montalva, Historia de los partidos políticos chilenos, Santiago, Editorial del Pacífico, 1949.

Encina, Francisco Antonio, Portales, Editorial Nascimento, tomo I, Santiago, 2. a edición, 1964.

Galdames, Luis, Estudio de la Historia de Chile, Santiago, Editorial Universitaria, 1911.

García-Huidobro B., Cristóbal, Reseña del libro «Construcción de Estado en Chile (1800-1837)», Historia, n. ${ }^{\circ}$ 40, vol. I, Santiago, 2007, pp. 194-198.

Gay, Claudio, Historia Física y Política de Chile, tomo VIII, París, editado en casa del autor, 1871.

Gazmuri, Cristián, «Edwards y la Fronda Aristocrática», Historia, vol. 37, n. ${ }^{\circ}$ 1, Santiago, 2004, pp. 61-95.

—, La bistoriografía chilena (1842-1920), tomo I, Santiago, Taurus, 2006.

Góngora, Mario, Ensayo bistórico sobre la noción de Estado en Chile en los siglos XIX y XX, Santiago, Editorial Universitaria, 8. ${ }^{a}$ edición, 2003.

González Marrero, Secundino, «Anarquismo», en Reyes, Román (dir.), Diccionario Crítico de Ciencias Sociales. Terminología Cientifico-Social, tomos 1-4, Madrid-México, Ed. Plaza y Valdés, 2009.

Heise González, Julio, 150 años de evolución institucional, Santiago, Andrés Bello, 1960.

—, «Colección de Apuntes de Clases n. ${ }^{\circ}$ 3», Historia Constitucional de Chile, Santiago, Universidad de Chile, 1959.

—, Años de formación y aprendizaje político 1810-1833, Santiago, Editorial Universitaria, 1978.

Iggers, Georg G., La historiografía del siglo XX. Desde la objetividad cientifica al desafío posmoderno, Santiago, Fondo de Cultura Económica, 2012.

Infante, Francisco Javier, Autonomía, independencia y república en Chile, 1810-1828, Santiago, Centro de Estudios Bicentenario, 2014.

Jocelyn-Holt Letelier, Alfredo, El peso de la noche, nuestra frágil fortaleza histórica, Santiago, Planeta/Ariel, 1998.

Lastarria, José Victorino, Obras Completas, tomo IX, Santiago, Imprenta Barcelona, 1906.

Levene, Ricardo, La anarquía del año 20, Buenos Aires, Unión de editores latinos S.R.L., 1954.

Loveman, Brian, Chile: The Legacy of Hispanic Capitalism, Nueva York, Oxford University Press, 1979.

Malatesta, Ericco, La Anarquía, Puebla, Premiá editora de libros S. A., 1989.

Márquez Ochoa, Boris, Anarquía en Chile: 1823-1830, ¿invención historiográfica o realidad históri- 
ca?, Tesis para optar al grado de Magister en Historia, Concepción, Universidad de Concepción, 2015.

Martínez, Fray Melchor, Memoria histórica sobre la Revolución de Chile desde el cautiverio de Fernando VII hasta 1814, Valparaíso, Imprenta Europea, 1848; reedición en dos volúmenes, por el Fondo Bibliográfico José Toribio Medina, Santiago, 1962 y 1964.

Mc Evoy, Carmen (ed.), Los Funerales Republicanos en América del Sur: Tradición, Ritual y Nación 1832-1896, Santiago, Centro de Estudios Bicentenario e Instituto de Historia Pontificia Universidad Católica de Chile, 2006.

Nicolas, Walter, Sobre el Anarquismo, Santiago, Editorial Eleuterio, 2016.

Luis Ossa, Juan, «La actividad política de Francisco Antonio Pinto: 1823-1828. Notas para una revisión biográfica», Historia, n. ${ }^{\circ}$ 40, vol. 1, Santiago, 2007, pp. 91-128.

Pedemonte, Rafael, Los acordes de la patria. Música y nación en el siglo XIX chileno, Santiago, Globo Editores, 2008.

Peralta, Paulina, ;Chile tiene fiesta!, el origen del 18 de septiembre (1810-1837), Santiago, Editorial LOM, 2007.

Promis Díaz, Fernando, reseña del libro Años de formación y aprendizaje político. 1810-1833, de Julio Heise, Editorial Universitaria, Santiago, 1978, Revista de Historia, Universidad de Concepción, año III, volumen III (segunda época), n. ${ }^{\circ}$ 3, Concepción, 1978, pp. 65-66.

Salazar, Gabriel, Construcción del Estado en Chile (1800-1837), Santiago, Editorial Sudamericana, 2005.

San Francisco, Alejandro, «La vida política», en Fermandois, Joaquín (dir.), Chile, Crisis imperial e independencia, tomo 1, Lima, 1808/1830, Taurus, 2010, pp. 39-88.

Silva Castro, Raúl, «Don Alberto Edwards», Revista Chilena de Historia y Geografía, n. ${ }^{\circ}$ 78, Santiago, 1933 , pp. $5-23$.

Silva Vargas, Fernando y Carlos Aldunate, editores, 1808 Historia de la república de Chile, Zig-Zag, Santiago, 2013, volumen I.

Sotomayor Valdés, Ramón, El Ministro Portales, Santiago, Ministerio de Educación Pública, 1954.

-, Historia de Chile bajo el gobierno del General Joaquín Prieto, Santiago, Academia Chilena de la Historia, 1962.

Stuven, Ana María y Cid, Gabriel, Debates republicanos en Chile. Siglo XIX, vol. I, Santiago, Ediciones Universidad Diego Portales, 2012.

Valencia Avaria, Luis, Símbolos Patrios, Santiago, Gabriela Mistral, 1974.

Villalobos, Sergio, Historia del pueblo chileno, Santiago, Zigzag, 1983.

—, «Sugerencias para un enfoque del siglo XIX», Colección de estudios CIEPLAN, n. ${ }^{\circ} 12$, Estudio n. ${ }^{\circ}$ 79, Santiago, 1984 , pp. 9-36.

—, Portales, una falsificación histórica, Santiago, Editorial Universitaria, 1989.

—, Osvaldo Silva, Fernando Silva y Patricio Estellé, Historia de Chile, Santiago, Editorial Universitaria, 2006.

-, Historia de los Chilenos, Santiago, Editorial Taurus, 2006-2010.

—, Estudios y ensayos en torno a la historia de Chile, Santiago, Editorial Universitaria, 2010.

Vitale, Luis, Interpretación Marxista de la Historia de Chile. La independencia política, la rebelión de las provincias y los decenios de la burguesía comercial y terrateniente, Santiago, Prensa Latinoamericana S.A., 1971.

White, Hayden, Metahistoria. La imaginación histórica en la Europa del siglo XIX, México D.F., Fondo de Cultura Económica, México, 2010. 